\title{
MOLECULAR CHARACTERIZATION OF NEWCASTLE DISEASE VIRUS ISOLATED FROM SAUDI ARABIA
}

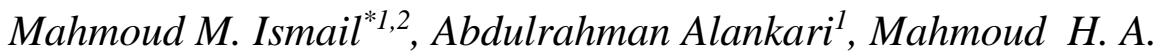 \\ Mohamed $^{1}$, Faris Elkhayat ${ }^{2}$ \\ ${ }^{1}$ Dept. of Clinical Studies, College of Veterinary Medicine and Animal Resources, \\ King Faisal University, Al-Hasa, Saudi Arabia \\ ${ }^{2}$ Dept. of Poultry Diseases, college of Veterinary Medicine, \\ Kafrelsheikh University, Egypt.
}

\begin{abstract}
A total of 34 samples were collected from chicken and pigeon flocks suspected to have Newcastle disease. NDV virus was isolated and identified by inoculation into the allantoic cavity of Specificpathogen- free chicken eggs followed by hemagglutination and hemagglutination inhibition test. Furthermore, these isolates were geno-typically analysed using RT-PCR with specific primers flanking a $270 \mathrm{bp}$ region representing the hypervariable region of $F$ gene and the PCR-product was sequenced and compared to the previously published sequences. In this study, the F protein of 34 Saudi NDV isolates phylogram revealed clustering with NDVs representing lineage 2,4 and 5 .
\end{abstract}

\section{INTRODUCTION}

Newcastle disease is a highly contagious and fatal disease of poultry that causes sever economic losses to the poultry industry allover the world, the disease is classified as list A disease by the OIE (Alexander, $2000 \&$ 2003). The disease is caused by avian paramyxovirus type 1 (APMV-1) (commonly known as Newcastle disease virus - NDV), a negative sense, non-segmented ssRNA virus belonging to the Avulavirus genus of Paramyxoviridae (Alexander et al., 
1986). According to the clinical disease and virus tropism the Newcastle disease virus (NDV) has been classified into the following five pathotypes: apathogenic enteric, lentogenic, mesogenic, viscerotropic velogenic, and neurotropic velogenic. Lentogenic NDV have low virulence, mesogenic NDV have middle virulence, while velogenic strains are the most virulent (Millar, Chambers \&Emmerson 1988; Alexander \& Senne, 2008; OIE, 2012).

The first reported outbreak occurred during 1926 on the island of Java, Indonesia. Subsequently, an outbreak of the disease was reported in the same year near Newcastle-on-Tyne, which led to its description the following year (Bruce et al. 2002; OIE 2004; Seal et al. 2002). Once the diseas has established in poultry, the worldwide spread of ND was probably the result of trade in live infected poultry and wild birds migration. Nowdays, ND has a worldwide distribution, and still one of the most important diseases threatening the poultry industury (Alexander et al. 1997; Miller et al., 2007). In order to control the ND outbreaks and spread, many countries around the world focus on biosecurity and intensive vaccination programs. The most widely used vaccinal strains during the last 6 decades have been LaSota and B1, which are class II, genotype II viruses (Alexander \& Senne, 2008).

There are many classifications of NDVs on the bases of antigenic and genotypic variations of their fusion $(\mathrm{F})$ protein and gene respectively (Alexander et al., 1999; Collins et al., 1993 \& 1998; Aldous et al. 2003). According to Aldous et al., (2003), the NDV has been classified into six broadly distinct groups (lineages 1 to 6 ). Lineages 3 and 4 were further subdivided into four sublineages (a to d) and lineage 5 into five lineages (a to e). He grouped all avirulent APMV-1 in lineage 1 and 
lineage 6. Another interesting work conducted by Czegledi et al. in 2006, where the authors described 2 classes of NDV (class I and class II) based on genomic data and sequencing of the $F$ as well as RNA-directed RNA polymerase (L) genes. These 2 classes contain all the previously described genotypes and lineages. The $\mathrm{F}$ gene was chosen for sequencing because this gene is a major determinant of virulence and NDV isolates are grouped into genotypes based on the sequences of this gene. The use of reverse transcriptase polymerase chain reaction (RTPCR) followed by direct sequencing and analysis of the fusion protein gene cleavage site, has been done for many NDV research and surveillance (Nuansrichay \& Chashing, 2008; Mohamed et al., 2011).

In Saudi Arabia, few information is available about the molecular chracterestics of the NDVs. Hence, in this study 34 isolates of NDV were collected from chicken farms in Al-Hasa province, SA. These isolates were geno-typically analyzed using RT-PCR with specific primers flanking a $270 \mathrm{bp}$ region representing the hypervariable region of $\mathrm{F}$ gene and the PCR-product was sequenced and compared to the previously published sequences.

\section{MATERIAL AND METHODS}

\section{Sample collection:}

A total of 34 samples in the present study were collected from commercial chicken farms and pigeon populations suffering from neurological and/or respiratory symptoms throughout the period of 2005-2008, Table(1). 
Virus isolation:

For virus isolation, samples were prepared and inoculated in SPF embryonated chicken eggs according to the international regulations (OIE, 2008). The allantoic fluid was collected 3 days post-inoculation and tested for haemagglutinating activity. Haemagglutinating agents were identified by means of haemagglutination inhibition (HI) tests using standard protocols (OIE, 2008).

\section{Molecular identification and characterization:}

Viral RNA extraction: for molecular testing, viral RNA was extracted from the 34 samples using the Nucleospin RNA II Kit (Machery-Nagel, Duren, Germany) and the detection of APMV-1 RNA was done using rRT-PCR protocol targeting the M gene (Wise et al., 2004).

\section{Nucleotide sequencing and genetic pathotyping:}

For genomic sequencing and genetic pathotyping, a 270-bp hypervariable region of the $\mathrm{F}$ gene encompassing the cleavage site (positions 4652-4917, with reference to NDV strain La Sota, GenBank accession number AF077761) was RT-PCR targeted. The F gene segment was amplified using primers NOH-For (50-TACACCTCAT CCCAGACAGG- 30) and NOH-Rev (50-AGTCGGAGGATGTTG GCAGC- 30) carried out in 50 $\mu 1$ reaction using Qiagen one-step RTPCR kit (Qiagen, Hilden, Germany). Amplicons were purified and sequenced using the Big Dye Terminator v3.1 cycle sequencing kit (Applied Biosystem, Foster City, CA, USA). The products were cleaned using PERFORMA DTR Ultra 96-Well kit (Edge BioSystems, Gaithersburg, MD, USA) and sequenced in a 16-capillary ABI PRISM 3130xl Genetic Analyzer (Applied Biosystems, Foster City, CA, USA). 


\section{Phylogenetic analysis:}

To determine the phylogenetic relationships between analysed strains, a region of $(300 \mathrm{pb})$ of the $\mathrm{F}$ gene of 34 APMV-1 sequences obtained in this study and corresponding sequence of ND viruses available in GenBank (http:// www.ncbi .nlm.nih.gov/) were used to construct the fusion gene tree. The lineage-based nomenclature illustrated in a previous study (Aldous et al., 2003) was adopted. Nucleotide sequences were aligned and phylogenetic analysis was performed using the neighbour-joining method in the MEGA 4 programme (Tamura et al., 2007).

\section{RESULTS}

The RT-PCR amplified the fragment of F gene of Newcastle viruses, and then amplified products were sequenced. All the viruses, evaluated by RT-PCR followed with nucleotide sequencing, contained a virulent fusion protein cleavage site represented by the motifs ${ }^{112}$ RRQKRF $^{117}$ and avirulent fusion protein motif ${ }^{112}$ GRQGRL ${ }^{117}$ as indicated in Table 1. Thirty-three NDVs have multiple basic amino acids at the cleavage site, with the phenylalanine at 117 aa position at the $\mathrm{N}$ terminus of the F1 protein, which is a typical molecular marker of velogenic strains. Only one isolate (ID. $\mathrm{n}^{\circ} 328$ ) demonstrated molecular characteristics of lentogenic strains.

The phylogenetic analysis of 34 Saudi Arabian isolates revealed the co-circulation of three distinct clusters according to classification by Aldous et al., 2003. In particular the samples (ID. $\mathrm{n}^{\circ} 473,661,310,589$, $595,668,588,320,321,475,372,445,312,796,531,628,824,837$, $508,498,281,551,55,93,1302,108,681,139,22,110)$ belong to lineage 5 , the samples (ID. $\mathrm{n}^{\circ} 61 \mathrm{~A}, 61 / \mathrm{B}, 61 / \mathrm{C}$ ) fell in the lineage 4 , only sample (ID. $\mathrm{n}^{\circ} 328$ ) belonged to linage 2 . 
Mahmoud M. Ismail et., al.

Table (1): Gene F Cleavage site sequences and APMV-1 typing according to Aldous et al., 2003.

\begin{tabular}{|c|c|c|c|c|c|c|c|}
\hline Serial & Year & $\begin{array}{c}\text { Reference } \\
\text { number }\end{array}$ & $\begin{array}{c}N^{\circ} \text { VIR : } \\
\text { 08VIR/3489 }\end{array}$ & $\mathrm{N}^{\circ}$ RS:08RS/1178 & Cleavage site & Lineage & Host \\
\hline 1 & \multirow{7}{*}{2005} & 473 & 08VIR/3489 1-473 & 08RS/1178 1-473 & SGGRRQKRF & LINEAGE 5 & CHICKEN \\
\hline 2 & & 661 & 08VIR/3489 2-661 & 08RS/1178 2-661 & SGGRRQKRF & LINEAGE 5 & CHICKEN \\
\hline 3 & & 310 & 08VIR/3489 3-310 & 08RS/1178 3-310 & SGGRRQKRF & LINEAGE 5 & CHICKEN \\
\hline 4 & & 589 & 08VIR/3489 4-589 & 08RS/1178 4-589 & SGGRRQKRF & LINEAGE 5 & CHICKEN \\
\hline 5 & & 595 & 08VIR/3489 5-595 & 08RS/1178 5-595 & SGGRRQKRF & LINEAGE 5 & CHICKEN \\
\hline 6 & & 668 & 08VIR/3489 6-668 & 08RS/1178 6-668 & SGGRRQKRF & LINEAGE 5 & CHICKEN \\
\hline 7 & & 588 & 08VIR/3489 7-588 & 08RS/1178 7-588 & SGGRRQKRF & LINEAGE 5 & CHICKEN \\
\hline 8 & \multirow{6}{*}{2006} & 320 & 08VIR/3489 8-320 & 08RS/1178 8-320 & SGGRRQKRF & LINEAGE 5 & CHICKEN \\
\hline 9 & & 321 & 08VIR/3489 9-321 & 08RS/1178 9-321 & SGGRRQKRF & LINEAGE 5 & CHICKEN \\
\hline 10 & & 475 & 08VIR/3489 10-475 & 08RS/1178 10-475 & SGGRRQKRF & LINEAGE 5 & CHICKEN \\
\hline 11 & & 372 & 08VIR/3489 11-372 & 08RS/1178 11-372 & SGGRRQKRF & LINEAGE 5 & CHICKEN \\
\hline 12 & & 445 & 08VIR/3489 12-445 & 08RS/1178 12-445 & SGGRRQKRF & LINEAGE 5 & CHICKEN \\
\hline 13 & & 312 & 08VIR/3489 13-312 & 08RS/1178 13-312 & SGGRRQKRF & LINEAGE 5 & CHICKEN \\
\hline 14 & \multirow{8}{*}{2007} & 796 & 08VIR/3489 14-796 & 08RS/1178 14-796 & SGGRRQKRF & LINEAGE 5 & CHICKEN \\
\hline 15 & & 531 & 08VIR/3489 15-531 & 08RS/1178 15-531 & SGGRRQKRF & LINEAGE 5 & CHICKEN \\
\hline 16 & & 628 & 08VIR/3489 16-628 & 08RS/1178 16-628 & SGGRRQKRF & LINEAGE 5 & CHICKEN \\
\hline 17 & & 824 & 08VIR/3489 17-824 & 08RS/1178 17-824 & SGGRRQKRF & LINEAGE 5 & CHICKEN \\
\hline 18 & & 837 & 08VIR/3489 18-837 & 08RS/1178 18-837 & SGGRRQKRF & LINEAGE 5 & CHICKEN \\
\hline 19 & & 508 & 08VIR/3489 19-508 & 08RS/1178 19-508 & SGGRRQKRF & LINEAGE 5 & CHICKEN \\
\hline 20 & & 498 & 08VIR/3489 20-498 & 08RS/1178 20-498 & SGGRRQKRF & LINEAGE 5 & CHICKEN \\
\hline 21 & & 281 & 08VIR/3489 21-281 & 08RS/1178 21-281 & SGGRRQKRF & LINEAGE 5 & CHICKEN \\
\hline 22 & \multirow{8}{*}{2008} & 551 & 08VIR/3489 22-551 & 08RS/1178 22-551 & SGGRRQKRF & LINEAGE 5 & CHICKEN \\
\hline 23 & & 55 & 08VIR/3489 23-55 & 08RS/1178 23-55 & SGGRRQKRF & LINEAGE 5 & CHICKEN \\
\hline 24 & & 93 & 08VIR/3489 24-93 & 08RS/1178 24-93 & SGGRRQKRF & LINEAGE 5 & CHICKEN \\
\hline 25 & & 1302 & 08VIR/3489 25-1302 & 08RS/1178 25-1302 & SGGRRQKRF & LINEAGE 5 & CHICKEN \\
\hline 26 & & 108 & 08VIR/3489 26-108 & 08RS/1178 26-108 & SGGRRQKRF & LINEAGE 5 & CHICKEN \\
\hline 27 & & 681 & 08VIR/3489 27-681 & 08RS/1178 27-681 & SGGRRQKRF & LINEAGE 5 & CHICKEN \\
\hline 28 & & 139 & 08VIR/3489 28-139 & 08RS/1178 28-139 & SGGRRQKRF & LINEAGE 5 & CHICKEN \\
\hline 29 & & 22 & 08VIR/3489 29-22 & 08RS/1178 29-22 & SGGRRQKRF & LINEAGE 5 & CHICKEN \\
\hline 30 & \multirow{3}{*}{2006} & $61 / \mathrm{A}$ & 08VIR/3489 30-61/A & 08RS/1178 30-61/A & SGGRRQKRF & LINEAGE 4 & PIGEON \\
\hline 31 & & 61/B & 08VIR/3489 31-61/B & 08RS/1178 31-61/B & SGGRRQKRF & LINEAGE 4 & PIGEON \\
\hline 32 & & $61 / \mathrm{C}$ & 08VIR/3489 32-61/C & 08RS/1178 32-61/C & SGGRRQKRF & LINEAGE 4 & PIGEON \\
\hline 33 & 2005 & 110 & 08VIR/3489 37-110 & 08RS/1178 37-110 & SGGRRQKRF & LINEAGE 5 & CHICKEN \\
\hline 34 & 2006 & 328 & 08VIR/3489 41-328 & 08RS/1178 41-328 & GGGRQGRL & LINEAGE 2 & CHICKEN \\
\hline
\end{tabular}

Kafrelsheikh Vet. Med. J. Vol. 14 No. 1 (2016) 


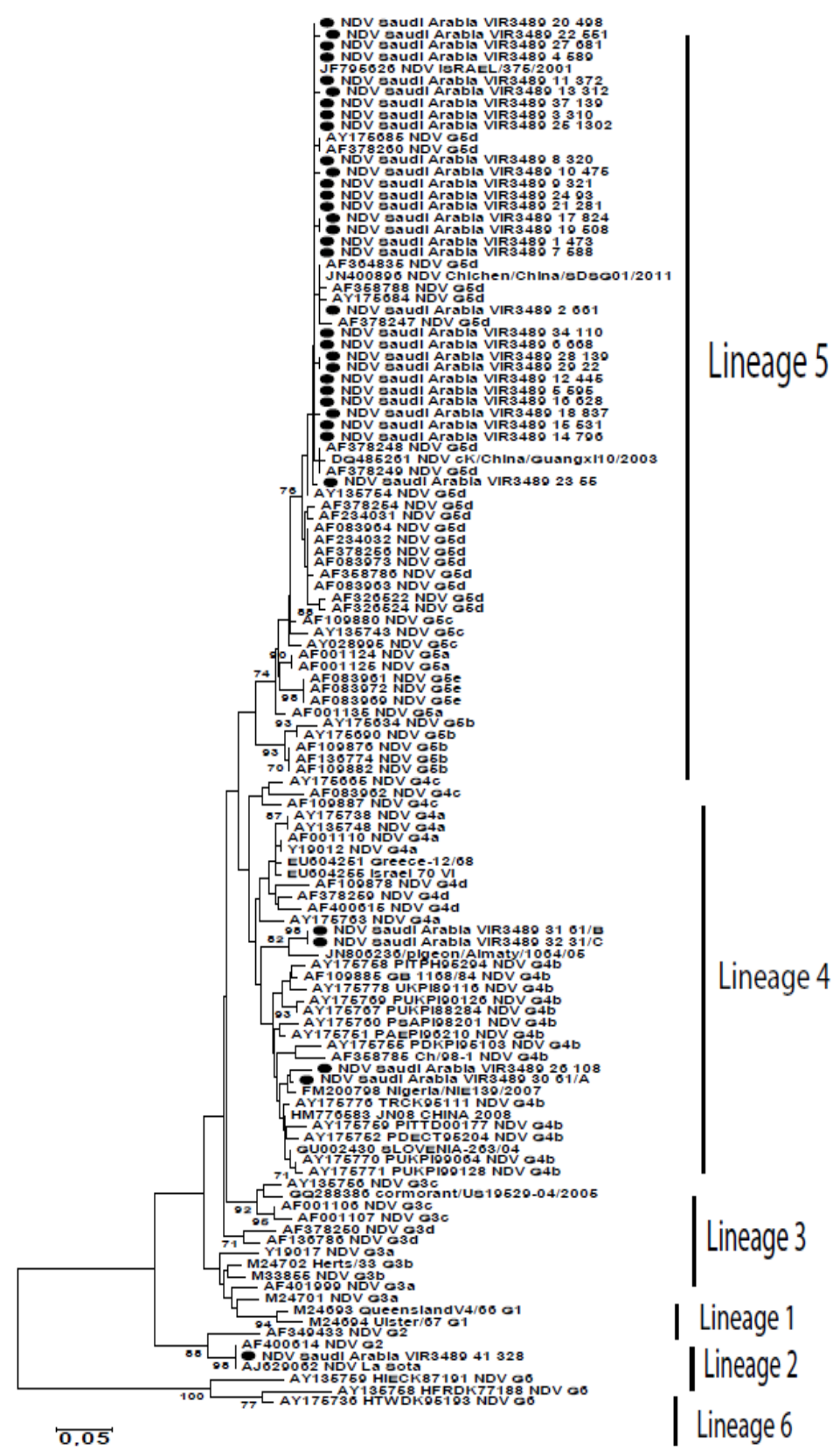

Fig. (1): Phylogenetic tree based on a $300 \mathrm{nt}$ segment of the gene F gene constructed by the neighbor-joining method with 1000 times bootstrapping. Sequences obtained in this study are labelled with a circle. 


\section{DISCUSSION}

Outbreaks of ND in Saudi Arabia poultry populations have been reported for many decades, the disease causes considerable loss to the poultry industry in terms of mortalities and drop in egg production. Consequently, NDV has become a constant threat to most poultry production units. In previous investigations studies focused on the virus isolation and serosurvillance of NDV in Saudi Arabia (El-Zein, 1986 and Al-Dubaib, 2010) NDV found to be widely spread in Saudi Arabia. Molecular investigation of NDV based on pathotyping using Real Time RT-PCR in Saudi Arabia have been established (Al-Habeeb, 2013). In this investigation, we conducted the first molecular study based on partial $\mathrm{F}$ gene sequence analysis of NDVs isolates from Al-Hasa province, Saudi Arabia.

In this study, the F protein of 34 Saudi NDV isolates phylogram revealed clustering with NDVs representing lineage 2,4 and 5 according to (Aldous, 2003). No insertion or deletions were found on these sequences. According to the available data of NDVs in different continents, NDVs belonging to lineage 5 are considered to be involved in outbreaks of Far East (Mase et al., 2002 \& Tan et al., 2008), also viruses belonging to lineage 5 has been reported in Africa (Abolnik et al., 2004) and Europe (Herczeg et al., 1999). The Saudi isolates were found to be closely related to NDVs isolated from china, this might be due to the migration of wild birds, a significant reservoir for NDVs, from eastern to western Asia (Alexander, 2003) or trading activities across regional or international boundaries. 
NDVs from pigeons belonged to lineage 4 NDVs, which have been previously isolated and characterized among domestic and wild birds in the middle east particularly United Arab Emirates and Saudi Arabia as well as European countries (Alexander, 2003). This finding provides an evidence that pigeon NDVs are circulating in birds since 2003 and the role of pigeon and other wild birds in the transmission and epidemiology of NDV to commercial poultry operations must be considered.

Isolate 320SA contains the classic vaccine motif (GGGRQGRL) of La Sota and B1 NDV strains where glutamine has replaced glycine (Kim et al., 2007), and clustered with viruses representing lineage 2 which consists primarily from viruses that had origin from North America varying from GB/Texas to B1 strains. This increase the hypothesis of being a vaccinal strain.

\section{CONCLUSION}

Recent outbreaks of ND in Saudi Arabia in spite of intensive use of vaccination. So continuous evaluation of vaccination program must be considered. The isolation of closely related NDV strains during period from 2005 to 2008 which clustered in lineage 5 or lineage 4 indicates that these strains are endemic and available vaccines are not highly effective to control the disease and minimize shedding of the virus leading to circulation of the virus in chicken flocks.

Acknowledgement: The authors would like to thank Deanship of Scientific Research, King Faisal University, for supporting this research. grant \# 120094. 


\section{REFERENCES}

- Herczeg J, Wehmann E, Bragg RR, Travassos Dias PM, Hadjiev G, Werner O, Lomniczi B: 1999. Two novel genetic groups (VIIb and VIII) responsible for recent Newcastle disease outbreaks in Southern Africa, one (VIIb) of which reached Southern Europe.Arch Virol, 144:2087-2099.

- Abolnik C, Horner RF, Bisschop SP, Parker ME, Romito M, Viljoen GJ: 2004. A phylogenetic study of South African Newcastle disease virus strains isolated between 1990 and 2002 suggests epidemiological origins in the Far East. Arch. Virol. 149:603-619.

- Tan LT, Xu HY, Wang YL, Qin ZM, Sun L, Liu WJ, Cui ZZ. 2008. Molecular characterization of three new virulent Newcastle disease virus variants isolated in China J. Clinical Microbiol. 46:750-753.

- Mase M, Imai K, Sanada Y, Sanada N, Yuasa N, Imada T, Tsukamoto K, Yamaguchi S. 2002. Phylogenetic analysis of Newcastle disease virus genotypes isolated in Japan. J Clin Microbiol 40:3826-3830.

- Aldous EW, Mynn JK, Banks J, Alexander DJ.(2003). A molecular epidemiological study of avian paramyxovirus type 1 (Newcastle disease virus) isolates by phylogenetic analysis of a partial nucleotide sequence of the fusion protein gene. Avian Pathol. 32 (3):239-56. 
- Capua, I., Alexander, D.J. (Eds.) (2009). Avian Influenza and Newcastle Disease, a Field and Laboratory Manual. SpringerVerlag, Italy, 19-26.

- OIE, 2008. Manual of Diagnostic Tests and Vaccines for Terrestrial Animals 2008. Available on the website: http://www. oie. int/ eng/normes/mmanual/A_summry.htm.

- Tamura K, Dudley J, Nei M, Kumar S. MEGA4: 2007 Molecular Evolutionary Genetics Analysis (MEGA) software version 4.0. Mol Biol Evol. 24:1596-9.

- Wise MG, Suarez DL, Seal BS, Pedersen JC, Senne DA, King DJ, Kapczynski DR, Spackman E. 2004. Development of a realtime reverse-transcription PCR for detection of newcastle disease virus RNA in clinical samples. J Clin Microbiol. Jan;42(1): 329-38.

- Miller PJ, King DJ, Afonso CL, Suarez DL. 2007. Antigenic differences among Newcastle disease virus strains of different genotypes used in vaccine formulation affect viral shedding after a virulent challenge. Vaccine 25:7238-7246.

- Nuansrichay B,Chashing A. 2008. Phylogenetic characterization of Newcastle disease viruses isolated in Thailand during 20062007. Thailand national institute of animal health e-Journal; 3 (2): 179-188. 